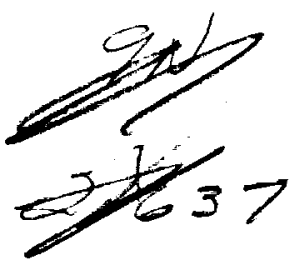

\title{
Numerical Investigation of Performance Degradation of Wings and Rotors due to Icing
}

NASA Grant NAG-3-768

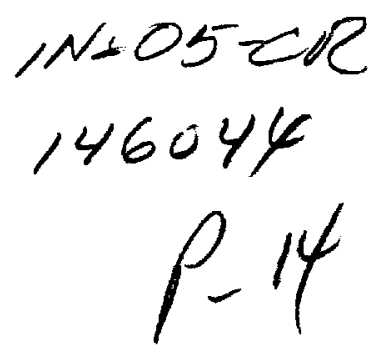

Progress Report for the Period January 1 - June 30, 1991

\author{
Submitted to \\ NASA Lewis Research Center \\ Cleveland, Ohio \\ Attn : Dr. Mark Potapczuk
}

Prepared by

Lakshmi N. Sankar

Professor

and

Oh J. Kwon

Post-Doctoral Fellow

School of Aerospace Engineering Georgia Institute of Technology

Atlanta, GA 30332

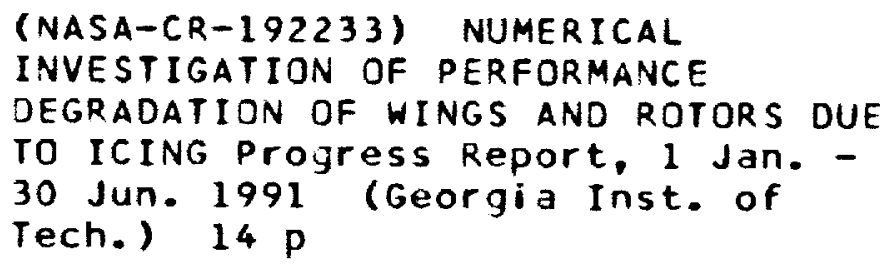




\section{INTRODUCTION}

During the past five years, under the support of the NASA Lewis Research Center, a research program related to aircraft and rotorcraft icing has been underway at Georgia Institute of Technology. The objectives of this effort are:

a) Develop solution techniques capable of computing 3-D unsteady viscous flow past wing-alone and rotor configurations subjected to icing,

b) Assess the performance degradation in the aerodynamic characteristics of these configurations due to icing.

This report summarizes the work carried out during the reporting period January 1 - June 30, 1991.

\section{PROGRESS DURING THE REPORTING PERIOD} completed.

During the reporting period the following tasks were

a) Fixed Wing Calculations:

In the previous fixed wing calculations [1,2], the aerodynamic surface pressures and the integrated sectional loads were compared with the experimental results for both clean and iced configurations. It was shown that the present method predicts accurate aerodynamic load distributions for both clean and iced configurations. It was also shown in Ref.3 that the wing root boundary condition has a significant effect on the distributed and integrated aerodynamic loading, particularly near the wing root for iced configurations. It was demonstrated that application of a noslip wall boundary condition at the wing root to simulate the splitter plate as in the experiment predicts higher effective angle of attacks at wing root sections and thus gives partially separated flow on the wing leading edge when compared with the results of symmetric boundary condition, which predicts fully separated flow at the wing root region. It was assumed that the wing root boundary condition has less significant effect on clean wing cases in the previous studies. In the present reporting period, additional cases have been studied for clean wing configurations with both wall and 
symmetric boundary conditions and the results have been compared to assess the effects of wall on clean wing configurations.

Fig.1 shows the comparison of chordwise pressure distributions between wall and symmetric boundary conditions at the wing root for a rectangular wing at $8 \mathrm{deg}$. angle of attack. It is shown that different boundary conditions at the wing root do not affect the chordwise aerodynamic loading significantly at least for the spanwise locations where experimental data is available. In Fig. 2 , the integrated sectional loading is compared between the two different boundary conditions. It is shown that the wall at the wing root tends to increase the sectional loading within $20 \%$ of the span due to the highly three-dimensional flow phenomenon at the intersection of the wall and the wing. The effect of wall is much less significant for the clean wing configurations than the iced wing cases, where the effect of wall dominate the flow features up to $60 \%$ of the span as shown in Ref. 3 .

A similar trend was obtained for a clean wing with $30 \mathrm{deg}$. leading edge sweep. The chordwise pressure distributions at 5 spanwise locations are compared with the experiment in Fig. 3 . It is shown that the effect of wall at the wing root is not significant for these spanwise stations and almost identical chordwise load distributions were obtained. The comparison of spanwise load distributions between the two boundary coriditions in Fig. 4 shows less than $3 \%$ of difference outside the $20 \%$ span. This demonstrates that the effect of wall is not significant for clean wing configurations for cases with finite leading edge sweep angle.

In addition to the studies about the wing root boundary conditions discussed above, an Euler calculation has been performed for the wing with $30 \mathrm{deg}$. leading-edge sweep at $8 \mathrm{deg}$. angle of attack in order to study the effects of viscosity on the wing performance under icing. In Fig. 5 it is shown that the chordwise pressure distribution using the inviscid Euler calculation does not compare well with the experiment, especially at the upper surface of the wing where a large region of flow separation exists. The integrated sectional load distribution in Fig. 6 shows that the Euler calculation predicts 10 to $20 \%$ higher loading than the viscous calculation and the experiment. The particle trajectory simulation in Fig. 7 and the surface oil flow simulation in Fig. 8 show that the Euler calculation predicts a smaller region of flow separation and 
does not produce a well organized vortical flow patten as in the Navier-Stokes calculation.

b) Helicopter Rotors in Forward Flight:

A typical two-bladed helicopter rotor with the solidity of 0.08861 was chosen as the baseline clean rotor. The rotor blade has a rectangular planform and uses NACA 0012 airfoil sections. This configuration was chosen because of the availability of experimental data for this rotor from NASA Lewis Research Center. No direct comparisons with experiments, however, are planned during this phase of the work. The same rotor with a simulated glaze ice on the blade leading-edge is being considered to be an iced rotor. It is assumed that the ice formation stretches from the blade root to the tip maintaining the same shape. For the present work, the tip Mach number was 0.40 and the tip Reynolds number was 2.2 millions based on the blade chord length. The computational $\mathrm{C}$-grid consisted of 135 streamwise points (115 on the wing surface), 38 spanwise points ( 33 on the wing), and 41 points in the normal direction.

Initially, the rotor disk was set at zero angle of attack and the advance ratio (forward flight speed/rotor rotational tip speed) of 0.2 to demonstrate the ability of the present method to calculate the non-lifting unsteady forward flight cases. The torque variation as a function of rotor azimuth angle is compared between the clean and iced rotors. In this way, the effects of a wake model on computed results can be eliminated and the effect of blade leading edge ice formation on the rotor torque obtained. Calculation of the 3-D viscous flow around helicopter rotors for a complete rotor revolution requires several tens of CPU hours even on most advanced supercomputers. Thus, the present work is one of the first few attempts to integrate the flow solver over the entire rotor plane in a time accurate mode. Fig.9 shows the integrated torque vs. rotor azimuth angle of one blade for the advancing side of the rotor plane. It is shown that the required torque of the iced rotor is 50 to $60 \%$ higher than the clean rotor. The torque variation as a function of rotor azimuth angle shows that higher torque is required when the rotor blade is at the downstream position of the rotor disk plane and minimum at the azimuth angle of $90 \mathrm{deg}$.. 


\section{PROPOSED RESEARCH DURING THE REMAINING PERIOD}

During the period July 1 - December 31, 1991, the following research tasks will be performed.

a) Additional experimental data for swept iced wing configurations are being obtained by Prof. Bragg at the University of Illinois including the detailed flow field measurement using the LDV technique. The final work for the remaining period will include correlations with this data.

b) Some additional Euler calculations will be performed for the different flight conditions. The sensitivity of the grid with different number and distribution will be tested based on the existing baseline calculations.

c) A limited set of calculations for lifting rotors in forward flight will be done for both clean and iced configurations. Both the spanwise load distribution and the integrated thrust and torque will be compared between the clean and iced rotors. The performance degradation due to the blade leading edge ice formation will also be described in detail. The results from a simplified lifting line method based on the experimental section aerodynamic coefficients will also be included for comparison.

\section{REFERENCES}

[1] Kwon, O. J. and Sankar, L. N., "Numerical Study of the Effects of lcing on Finite Wing Aerodynamics," Presented at the AIAA 28th Aerospace Sciences Meeting, Reno, Nevada, Jan. 8-11, 1990, AlAA Paper 90--0757.

[2] Kwon, O. J. and Sankar, L. N., "Numerical Study of the Effects of lcing on Fixed and Rotary Wing Performance," Presented at the AIAA 29th Aerospace Sciences Meeting, Reno, Nevada, Jan. 7-10, 1991, AIAA Paper 91--0662.

[3.] Sankar, L. N. and Kwon, O. J., "Numerical Studies of the Effects of lcing on Fixed and Rotary Wing Aircraft Aerodynamics," Annual Airfoil Performance-in-lcing Workshop, NASA Lewis Research Center, Sept. 14, 1990. 

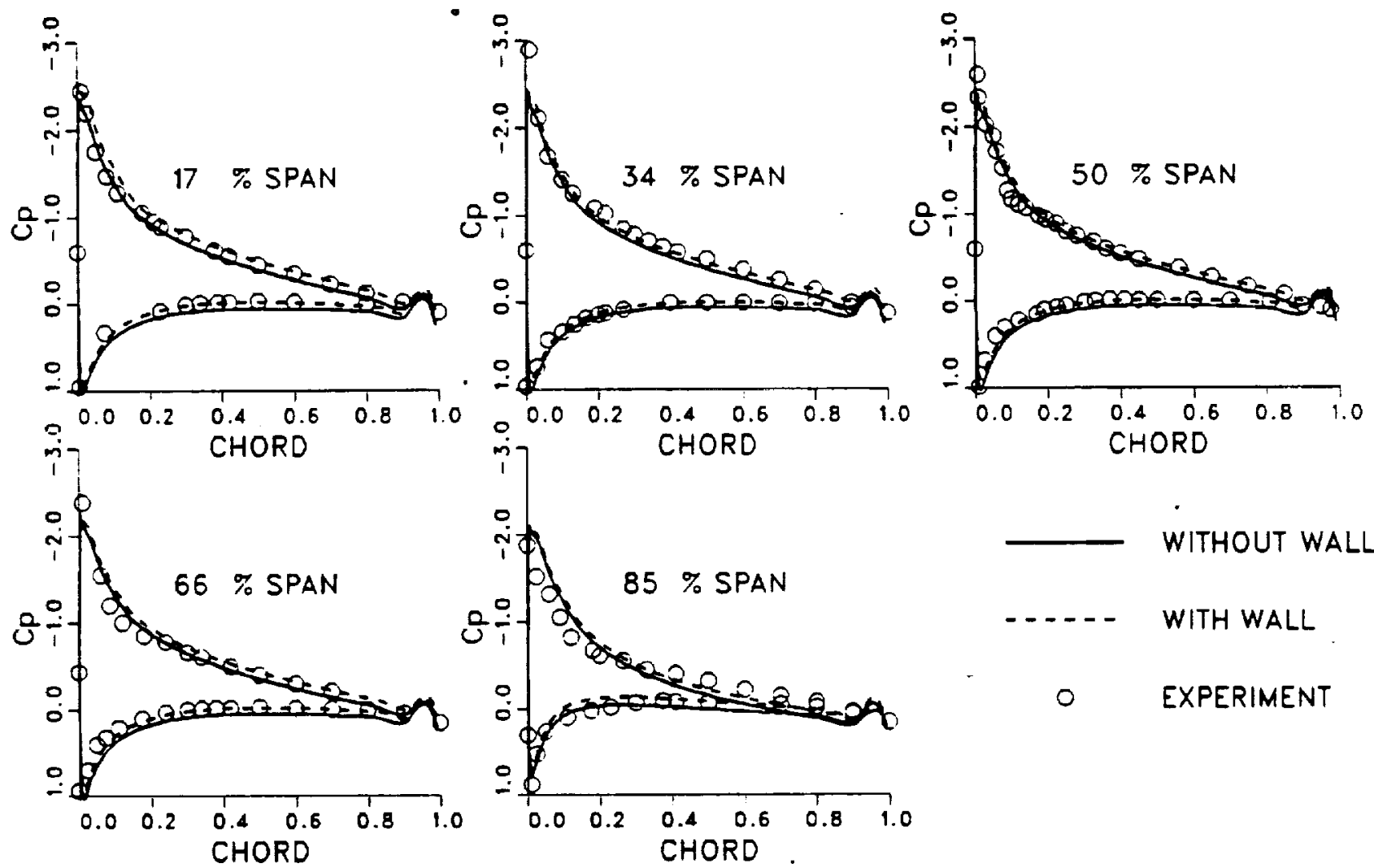

WITHOUT WALL

O EXPERIMENT

Fig. 1 Surface Pressure Distribution for Clean Rectangular Wing at $8 \mathrm{deg}$. Angle of Attack. 


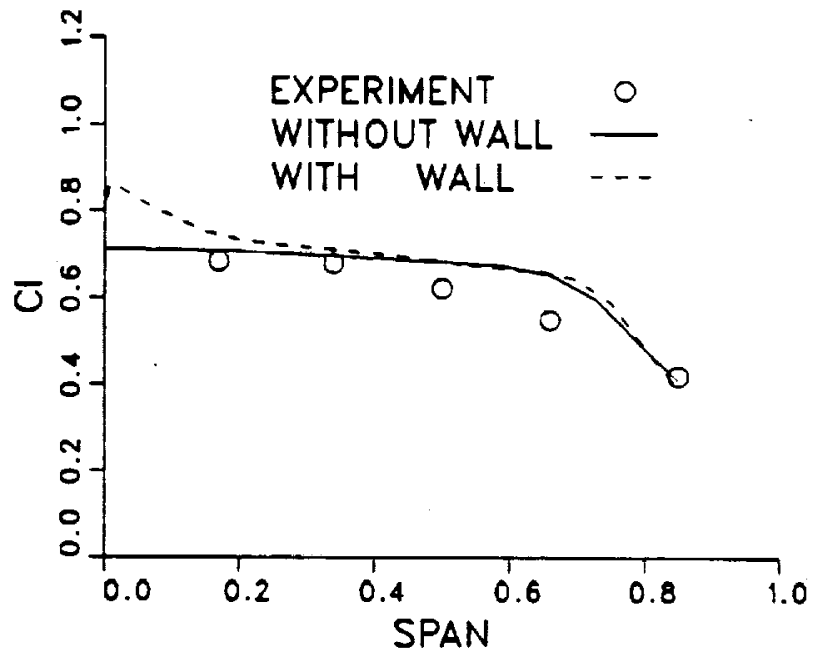

Fig. 2 Spanwise Load Distribution for the Clean Rectangular Wing at $8 \mathrm{deg}$. Angle of Attack. 


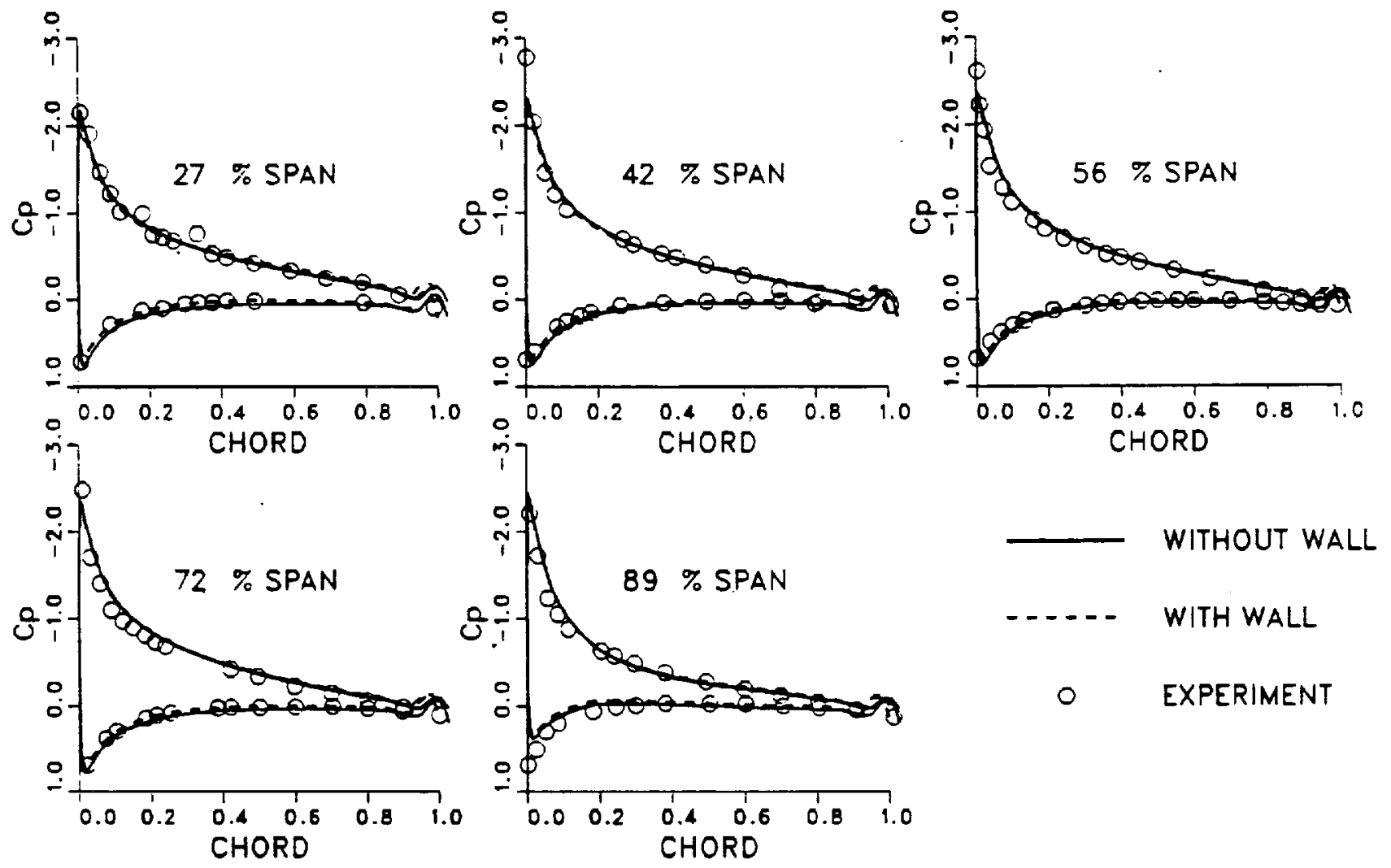

Fig. 3 Surface Pressure Distribution for Clean Swept Wing at $8 \mathrm{deg}$. Angle of Attack. 


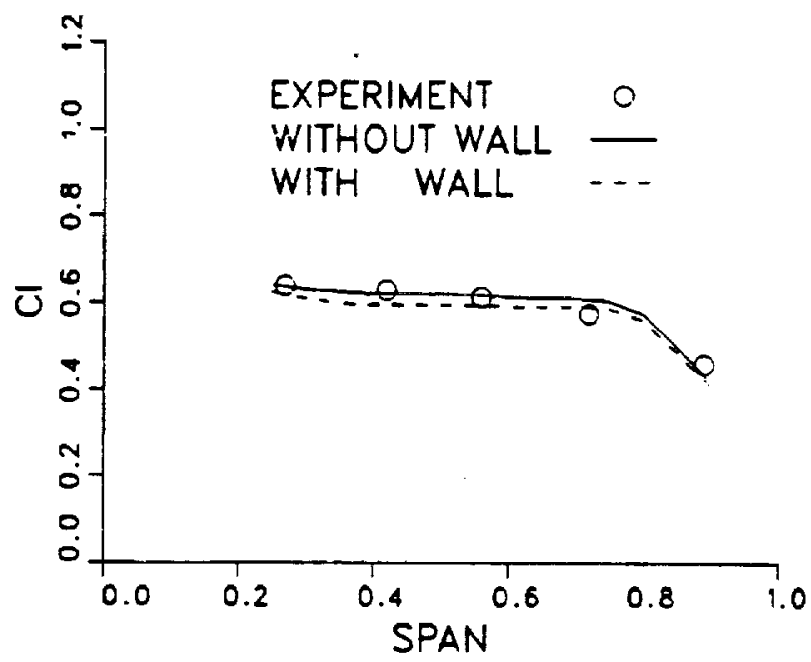

Fig. 4 Spanwise Load Distribution for the Clean Swept Wing at $8 \mathrm{deg}$. Angle of Attack. 

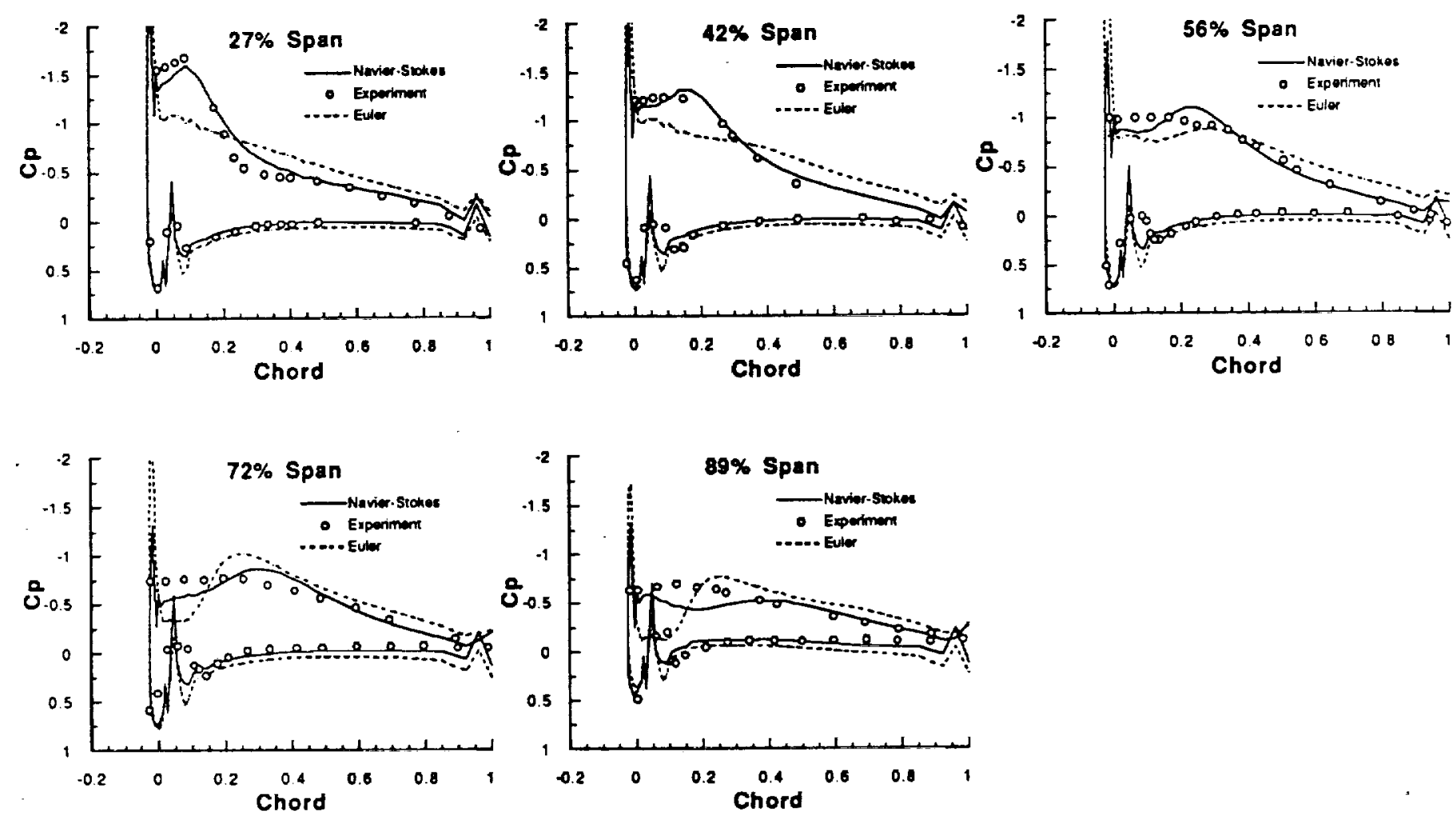

Fig. 5 Surface Pressure Distribution for lced Swept Wing at $8 \mathrm{deg}$. Angle of Attack. 


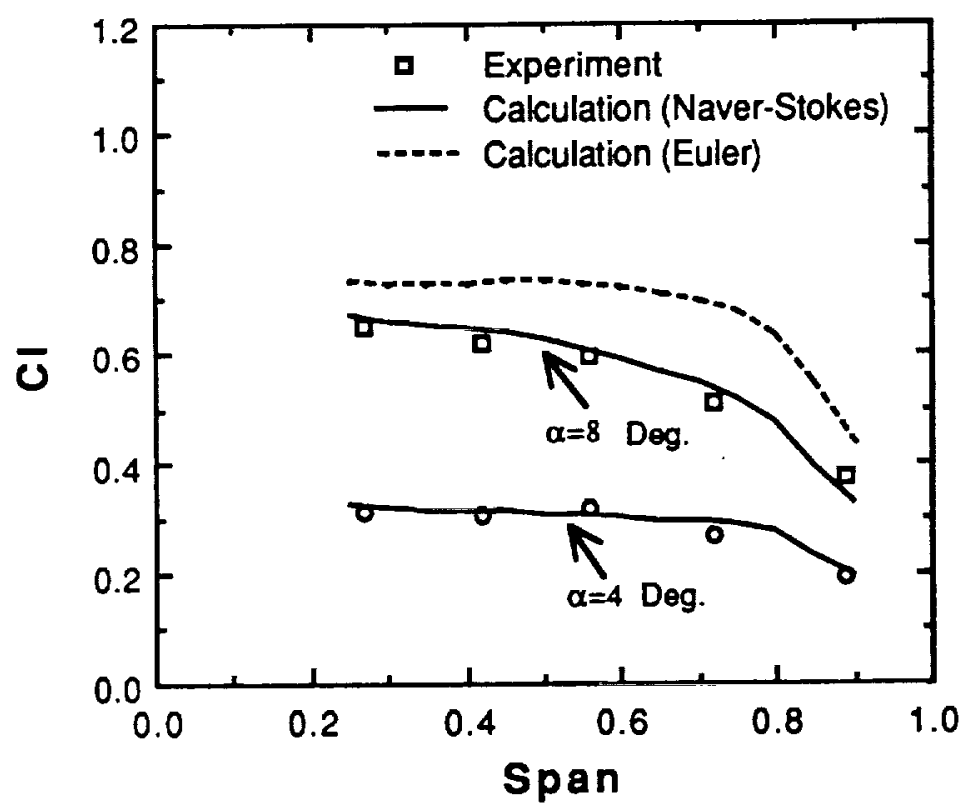

Fig. 6 Spanwise Load Distribution for the Iced Swept Wing at 4 and 8 deg. angles of attack. 

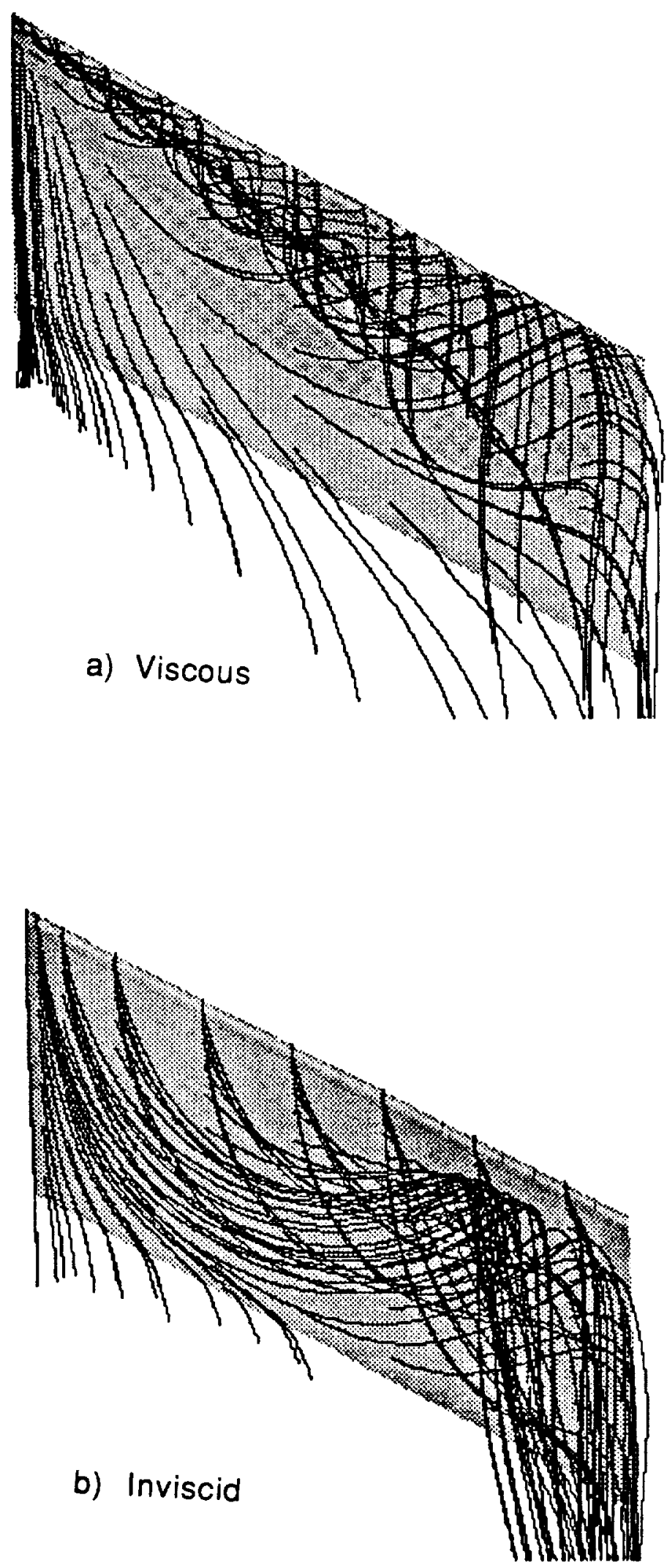

Fig. 7 Comparison of Particle Trajectory Simulations Between Viscous and Inviscid Calculations for the Iced Swept Wing at $8 \mathrm{deg}$. Angle of Attack. 

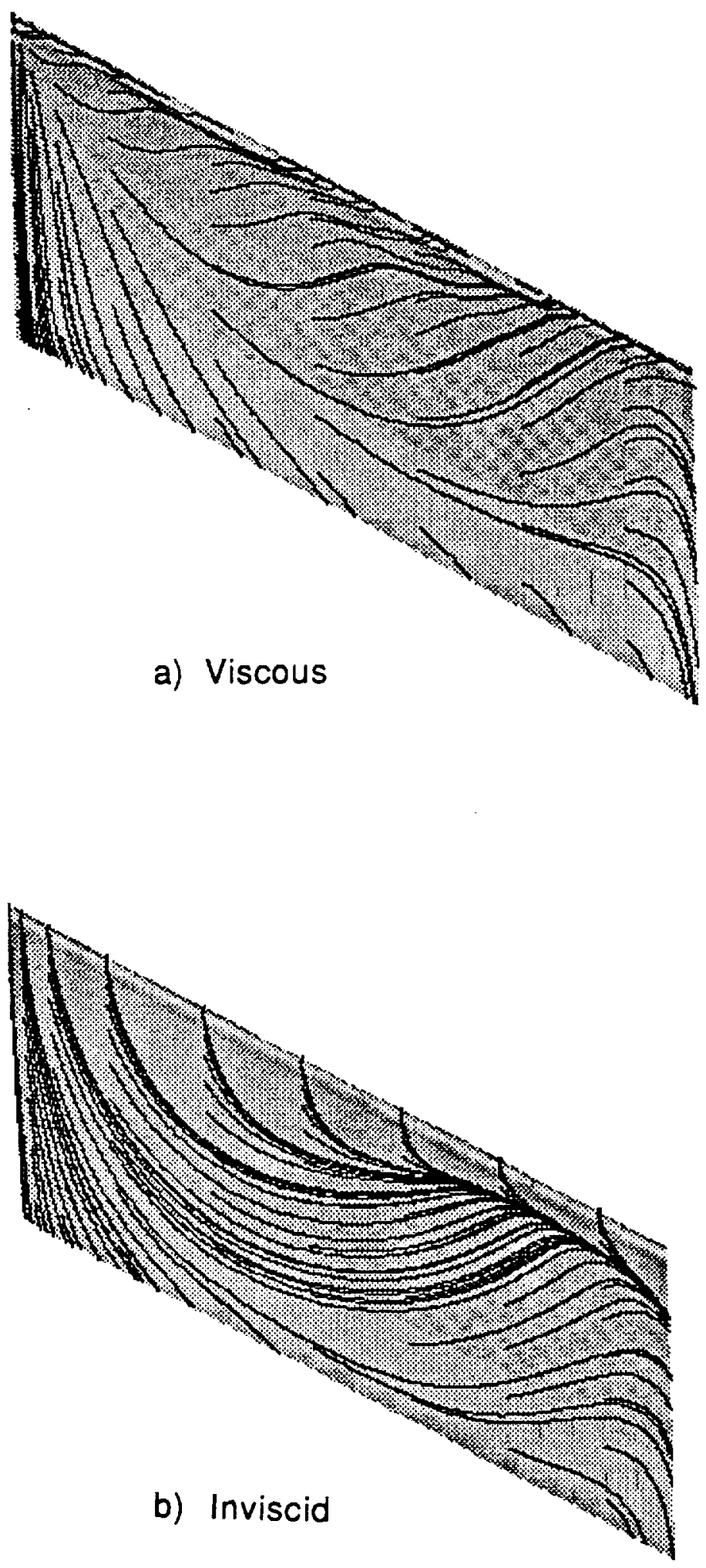

Fig. 8 Comparison of Surface Oil Flow Simulations Between Viscous and Inviscid Calculations for the Iced Swept Wing at $8 \mathrm{deg}$. Angle of Attack. 


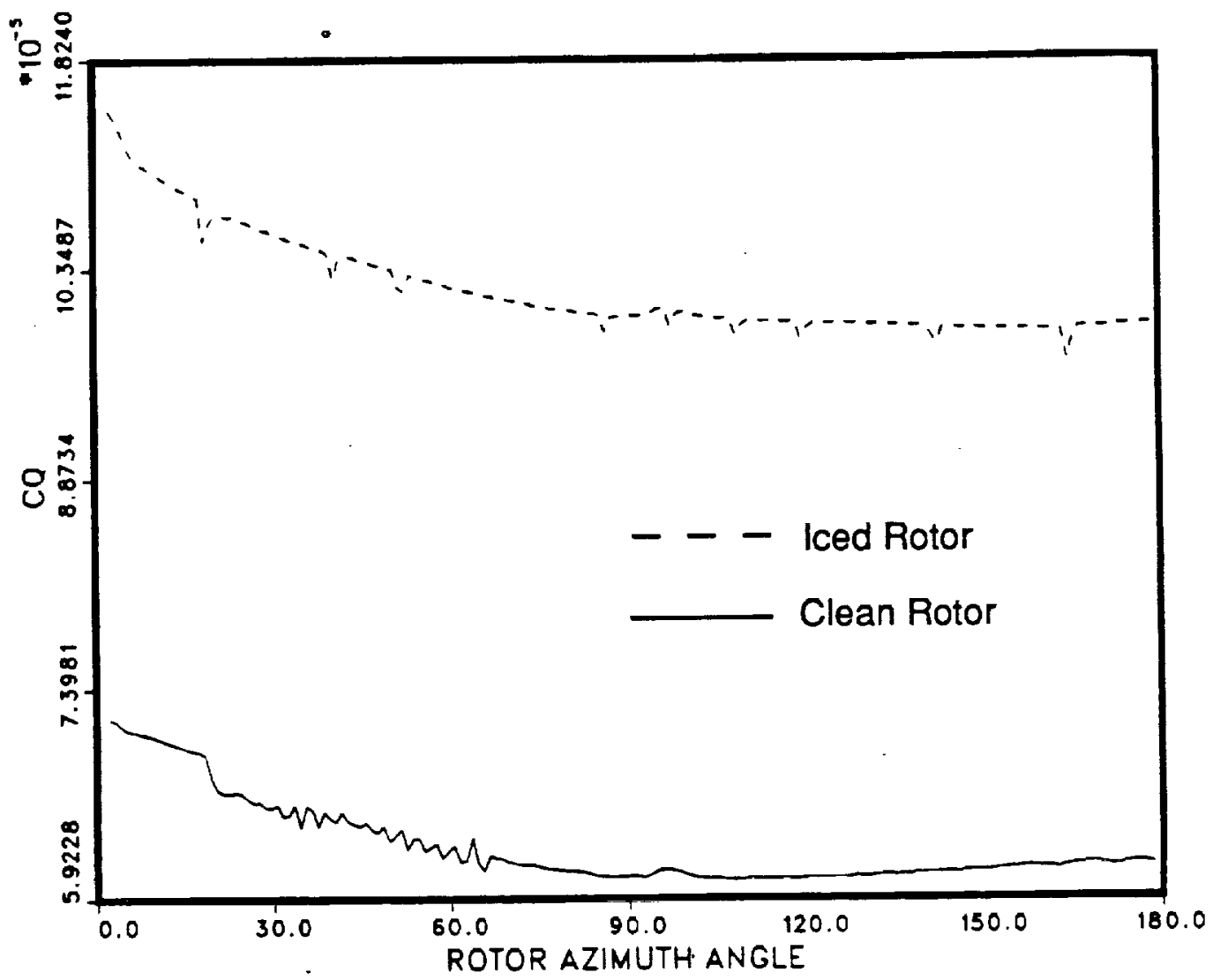

Fig. 9 Required Torque vs. Azimuth Angle for the Nonlifting Rotor in Forward Flight. 